\title{
Evidence of Neutral Radical Induced Analyte Ion Transformations in APPI and Near-VUV APLI
}

\author{
Hendrik Kersten, ${ }^{a}$ Valerie Funcke, ${ }^{\text {a }}$ Matthias Lorenz, ${ }^{\text {a }}$ \\ Klaus J. Brockmann, ${ }^{a}$ Thorsten Benter, ${ }^{a}$ and Rob O'Brien ${ }^{b}$ \\ a Department of Physical and Theoretical Chemistry, University of Wuppertal, Wuppertal, Germany \\ ${ }^{b}$ Department of Chemistry, The University of British Columbia-Okanagan, Kelowna, BC, Canada
}

\begin{abstract}
We report on the reactions of neutral radical species $\left[\mathrm{OH}, \mathrm{Cl}, \mathrm{O}\left({ }^{3} \mathrm{P}\right), \mathrm{H}\right]$, generated in a typical atmospheric pressure ionization (API) source upon irradiation of the sample gases with either $193 \mathrm{~nm}$ laser radiation or $124 \mathrm{~nm}$ VUV light, the latter commonly used in atmospheric pressure photoionization (APPI). The present investigations focus on the polycyclic aromatic hydrocarbon pyrene as representative of the aromatic compound class. Experimental results are supported by computational methods: simple kinetic models are used to estimate the temporal evolution of the concentrations of reactants, intermediates, and final products, whereas density functional theory (DFT) energy calculations are carried out to further elucidate the proposed reaction pathways. The neutral radicals are generated upon photolysis of background water and oxygen always present in appreciable mixing ratios in typical API sources. Substantial amounts of oxygenated analyte product ions are observed using both techniques. In contrast, upon atmospheric pressure laser ionization (APLI) with $248 \mathrm{~nm}$ radiation, oxygenated products are virtually absent. In addition, kinetic data evaluation yielded a bimolecular rate constant of $\mathrm{k}=(1.9 \pm 0.9) \times 10^{-9} \mathrm{~cm}^{3}$ molecule ${ }^{-1} \mathrm{~s}^{-1}$ for the reaction of the pyrene radical cation with $\mathrm{OH}$ radicals. (J Am Soc Mass Spectrom 2009, 20, 1868-1880) @ 2009 Published by Elsevier Inc. on behalf of American Society for Mass Spectrometry
\end{abstract}

A mong the variety of atmospheric pressure ionization (API) methods, atmospheric pressure laser ionization (APLI) has proven to be an extremely sensitive method for the detection of nonpolar aromatic compounds for applications in LC-MS and GC-MS [1-3]. Along with atmospheric pressure photoionization (APPI), both methods close the "analyte polarity gap" previously left open by electrospray ionization (ESI) and atmospheric pressure chemical ionization (APCI). With respect to sensitivity, APLI outperforms all other API methods by orders of magnitudes. Accordingly, APLI has become a powerful alternative to all other API methods for the ultra-trace detection of PAHs [4]. Recently, derivatization of functionalized nonaromatic compounds (e.g., alcohols, amines, and organic acids) with suitable REMPI labels propelled the APLI technique into numerous new analytical application fields [5]. The commonly used laser systems for the analytical application of APLI are UV $\mathrm{KrF}^{*}$ excimer lasers, radiating at a wavelength of $248 \mathrm{~nm}$. Alternatively, near-VUV $193 \mathrm{~nm} \mathrm{ArF*} \mathrm{excimer} \mathrm{lasers} \mathrm{may} \mathrm{be}$ used for selected high-energy applications. However, it was shown within the framework of the present exper-

Address reprint requests to Dr. H. Kersten and Dr. T. Benter, Department of Physical Chemistry FB-C, University of Wuppertal, Gauss Str. 20, 42119 Wuppertal, Germany. E-mail: hkersten@uni-wuppertal.de and tbenter@ uni-wuppertal.de iments that with $193 \mathrm{~nm}$ excitation, the linear response of solvent flow containing a fixed concentration of analyte versus analyte signal is severely affected. This is hardly observed with $248 \mathrm{~nm}$ excitation. Here, all matrix compounds (solvents, $\mathrm{N}_{2}, \mathrm{O}_{2}, \mathrm{H}_{2} \mathrm{O}$, etc.) are virtually transparent, whereas strong absorption starts around $200 \mathrm{~nm}$. At $124 \mathrm{~nm}$, frequently used for APPI, most solvents in addition to $\mathrm{O}_{2}$ and $\mathrm{H}_{2} \mathrm{O}$ exhibit absorption cross sections in the $10^{-17} \mathrm{~cm}^{2}$ molecule ${ }^{-1}$ regime [6-13]. Thus, in typical LC-APPI measurements, the penetration depth of VUV light is less than $5 \mathrm{~mm}$. Absorption spectra in this region are mostly structureless, indicating excited-state lifetimes far below the collision rate of about $10^{9} \mathrm{~s}^{-1}$. In other words, most of the available VUV energy applied in APPI is coupled into the matrix, resulting in electronic excitations and/or extensive photolysis of matrix compounds and, hence, in formation of primary neutral radicals. This has been speculated before [14] but to the best of our knowledge has not been demonstrated experimentally. Le Page et al. [15] investigated the reactions of radical cations of selected polyaromatic compounds with neutral radicals at reduced pressure. They reported bimolecular reaction rate constants about $10^{-10}$ up to $10^{-9}$ $\mathrm{cm}^{3} \cdot$ molecules ${ }^{-1} \cdot \mathrm{s}^{-1}$. Partly due to polarization effects [16], selected rate constants lead to reaction rates even faster than the calculated gas kinetic collision rate 
assuming collision cross sections of the corresponding neutral precursors. In addition to the above excitation pathways, Penning ionization may become an important route in the complex ionization mechanisms prevailing when VUV radiation is used as excitation source. We thus speculate that there must exist a rich neutral radical ion chemistry in an API source upon photoionization below wavelengths of $200 \mathrm{~nm}$.

\section{Experimental}

\section{Chemicals}

Methanol $(\mathrm{MeOH})$, acetonitrile $(\mathrm{ACN})$, and tetrachloromethane $\left(\mathrm{CCl}_{4}\right)$ were obtained from Fisher Scientific, Waltham, MA, USA. Pyrene was purchased from Merck KGaA, Darmstadt, Germany. Oxygen and nitrogen gas were from Gase.de, Sulzbach, Germany, with a stated purity of $99.9995 \%$ vol., respectively. All solvents were of analytical or chromatographic purity, all other chemicals of highest purity available, and were used without further purification.

\section{Instrumentation/Methods}

All mass spectrometric measurements were performed with an esquire6000 quadrupole ion trap (Bruker Daltonik $\mathrm{GmbH}$, Bremen, Germany) equipped with a commercially available APCI/APPI source as shown in Figure 1, top, or, for the mechanistic studies, a homebuilt ionization setup as shown in Figure 1, bottom. Pulsed laser radiation was obtained from an $\mathrm{ArF}^{*}$ or a $\mathrm{KrF}^{*}$ excimer laser (OPTex, Lambda Physik, Göttingen, Germany), radiating at wavelengths of 193 and $248 \mathrm{~nm}$, respectively. Pulse energies within the ion source were in the range of 1 to $1.7 \mathrm{~mJ}$ per pulse, with a pulse duration of $10 \mathrm{~ns}$ and a rectangular beam profile of $1 \mathrm{~cm}^{2}$ accounting for a power density of about $10^{5} \mathrm{~W} \mathrm{~cm}^{-2}$.

For routine APLI measurements, the Bruker Apollo APPI source (Figure 1, top) was used in the original configuration with the exception that one glass window is replaced by a quartz window. The unfocused laser beam is positioned 5 to $10 \mathrm{~mm}$ in front of the spray shield. It is noted that the Apollo source is not a tightly sealed compartment. The source is connected to a vent, which is held at a slightly reduced pressure and the windows as well as the nebulizer stage are mounted to the source body without vacuum seals.

The home-built ion source (Figure 1, bottom) is designed for operation with gaseous compounds only. It consists of a $25 \mathrm{~cm}$ long quartz tube, with an i.d. of 8 $\mathrm{mm}$, directly attached and sealed to the transfer capillary of the mass spectrometer. A $4 \mathrm{~mm}$ i.d. Pyrex tube, entirely opaque for VUV and UV light, is coaxially placed in the center of the quartz tube and ends $6 \mathrm{~cm}$ upstream of the MS transfer capillary. The $193 \mathrm{~nm}$ (VUV) laser beam is directed $5 \mathrm{~mm}$ upstream of the glass tube and the $248 \mathrm{~nm}$ (UV) laser beam $5 \mathrm{~mm}$ downstream of the glass tube exit. In this way the

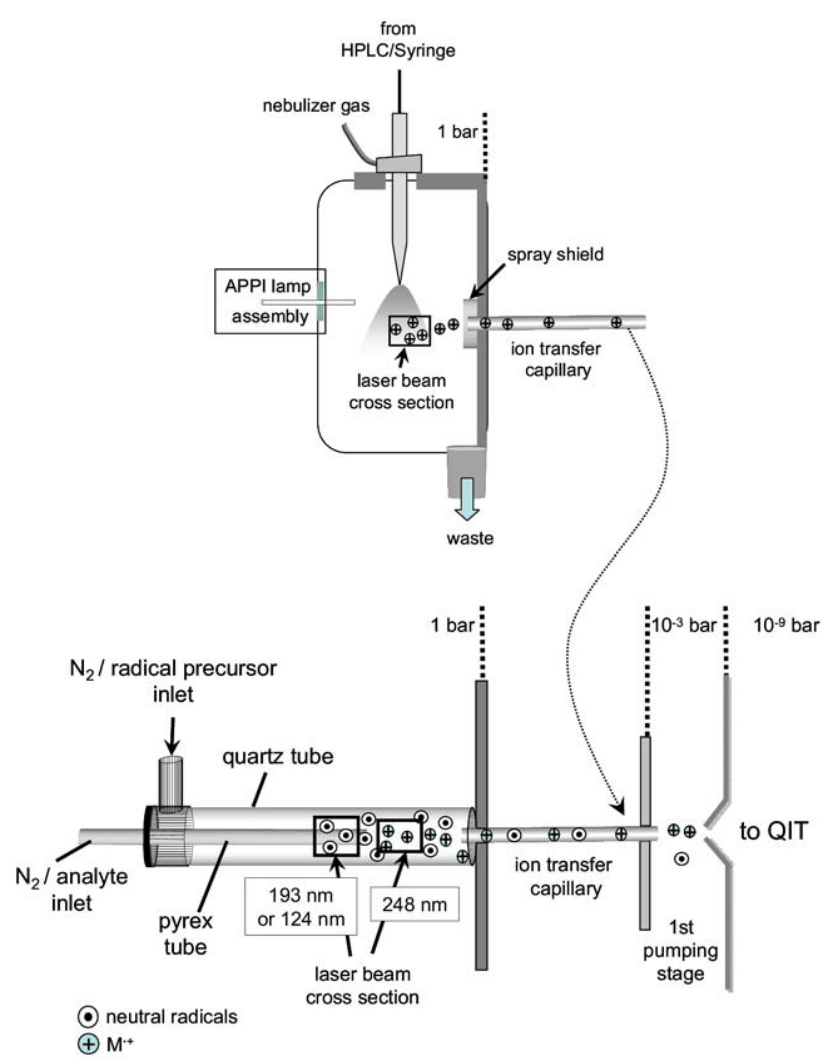

Figure 1. Schematic of the API sources used in the present investigation. Top: commercially available Bruker Apollo source for APPI and APLI operation. Bottom: home-built ionization setup for kinetic and mechanistic studies.

analyte, delivered through the inner glass tube, is not exposed to the VUV radiation, but ionized with UV radiation. However, the VUV laser is able to produce significant amounts of neutral atoms and radicals upon photolysis of precursors such as $\mathrm{O}_{2}, \mathrm{H}_{2} \mathrm{O}, \mathrm{CH}_{\mathrm{n}} \mathrm{Cl}_{4-\mathrm{n}}$ $(n=0-2)$, which are delivered in a controlled fashion within the bulk gas flow surrounding the inner glass tube. Hence, this setup spatially separates the 2-photon UV laser ionization region of the analyte from the production zone of neutral radicals by 1-photon VUV laser photolysis. The total gas flow is held constant at $1400 \mathrm{~cm}^{3} \mathrm{~min}^{-1}$. This closely matches the experimentally determined gas flow through the transfer capillary with the atmospheric pressure ionization region held at 970 mbar and the first MS pumping stage at 4 mbar. The averaged coaxial flow through the quartz reactor tube is calculated to be $46 \mathrm{~cm} \mathrm{~s}^{-1}$, resulting in a Reynolds number of $\operatorname{Re}=210$. Hence, the transport through this setup is essentially laminar, allowing for rather accurate calculations of the residence times and, thus, the reaction times. Additionally, this setup can be pumped down to roughly 1 mbar in a few seconds simply by shutting off the supply gases.

Nitrogen as the main carrier gas is supplied either by a nitrogen generator (UHP LCMS 18, Domnick Hunter, Gateshead, UK) for operation of the standard APPI/ APCI source or by high purity nitrogen from com- 
pressed gas cylinders for the home-built setup. The gas flow is regulated either by the inbuilt flow controller of the MS and/or by external mass flow controllers (1179A Mass-Flo-Controller, 2000 sccm; MKS Instruments, Andover, MA, USA) connected to a $647 \mathrm{C}$ multi-gas-controller unit (MKS Instruments). Liquid compounds are transferred to the gas phase using stainless steel cryo-traps, in which the saturation vapor pressure of a compound at constant temperature is balanced with nitrogen to a total pressure of $3000 \mathrm{mbar}$. The flow controllers allow for an accurate delivery of the compounds to the carrier gas. The final concentration in the reactor is calculated from the known vapor pressure at room temperature, the mixing ratio after pressurizing with nitrogen, and the mixing ratio within the total flow. The delivery of gaseous pyrene is accomplished by equilibrating the saturation vapor of deposited solid pyrene on the walls in the tube system with the main gas flow. This results in a constant pyrene mixing ratio of max. $6 \mathrm{ppbV}$, calculated using a pyrene saturation vapor pressure of $6 \times 10^{-6} \mathrm{mbar}$ at $25^{\circ} \mathrm{C}$ [17] and a total pressure of 970 mbar in the ion source. For operation of the commercial APPI source, liquid samples are delivered with a syringe pump (model 100; KD Scientific, Holliston, MA, USA) and transferred to the gas phase by pneumatically assisted thermal vaporization.

All gas flow calibrations are performed with a wetmeter TG05 (Ritter Apparatebau $\mathrm{GmbH}$ and Co. KG, Bochum, Germany). The ozone measurements are carried out with a Thermo environmental $49 \mathrm{O}_{3}$ analyzer (Thermo Environmental Instrument Corporation, Waltham, MA, USA).

Data acquisition was done with the MS data analysis software and for post-processing the data analysis 3.4 software suite (both Bruker Daltonik, Bremen, Ger- many) was used. All reported mass spectrometric information was gathered from the average of $\sim 1000$ single QIT scans.

\section{Computational Investigations}

Kinetic simulations. Kinetic simulations were performed with the Chemked-I/II version 3.3 software package [18] running on a personal computer. All rate constants used were based on standard thermodynamic conditions, as summarized in Table 1.

Potential energy calculations. Gaussian 03W [20] combined with the graphical user interface GaussView 4.1 [21] was used for potential energy calculations along the proposed reaction pathways. The reported Gibbs freeenergy and enthalpy corrected total energies were obtained from geometry optimizations and subsequent frequency calculations using the density functional theory (DFT) with the Becke-3-Parameter-Lee-Yang-Parr functional (B3LYP) and the $6-31++\mathrm{G}(\mathrm{d}, \mathrm{p})$ doubly-diffuse and doubly-polarized split-valence basis set. The combination of this functional and basis set type provide the optimal cost-to-benefit ratio with respect to CPU time [22], and has been satisfactorily applied to a large number of comparable reaction systems [23-26].

\section{Results and Discussion}

\section{Neutral Radical Formation and Reactions}

The speculated key radicals and atoms potentially responsible for the oxidation of analytes within the ion source are $\mathrm{O}\left({ }^{3} \mathrm{P}\right), \mathrm{OH}, \mathrm{H}$, and $\mathrm{Cl}$, generated upon

Table 1. Neutral radical reactions considered in the present investigation

\begin{tabular}{|c|c|c|c|}
\hline No. & Reaction & Rate constant $\mathrm{k}^{\mathrm{a}}$ & $\begin{array}{c}\text { Absorption cross section } \\
\sigma\left[\mathrm{cm}^{2} \text { molecule }\right. \\
193 \mathrm{~nm} / 124 \mathrm{~nm}^{\mathrm{b}}\end{array}$ \\
\hline 1 & $\mathrm{O}_{2}+\mathrm{h} \nu \rightarrow 2 \mathrm{O}\left({ }^{3} \mathrm{P}\right)$ & $22.5^{+}$ & $3 \cdot 10^{-22 / \sim 10^{-20}}$ \\
\hline 2 & $\mathrm{H}_{2} \mathrm{O}+\mathrm{h} \nu \rightarrow \mathrm{H}+\mathrm{OH}$ & $135^{+}$ & $1.8 \cdot 10^{-21} / \sim 10^{-17}$ \\
\hline 3 & $\mathrm{CH}_{\mathrm{n}} \mathrm{Cl}_{4-\mathrm{n}}(\mathrm{n}=0-2)+\mathrm{h} \nu \rightarrow \mathrm{CH}_{\mathrm{n}} \mathrm{Cl}_{4-\mathrm{n}-1(2)}+\mathrm{Cl}$ & $6.8 \cdot 10^{4+}$ & $9 \cdot 10^{-19} / \sim 10^{-17}$ \\
\hline 4 & $\mathrm{MeOH}+\mathrm{h} \nu \rightarrow \mathrm{MeO}+\mathrm{H}$ & $7.5 \cdot 10^{3+}$ & $10^{-19} / \sim 10^{-17}$ \\
\hline 5 & $\mathrm{O}_{3}+\mathrm{h} \nu \rightarrow \mathrm{O}\left({ }^{1} \mathrm{D}\right)+\mathrm{O}_{2}$ & $3 \cdot 10^{5+}$ & $4 \cdot 10^{-19 / \sim 10^{-17}}$ \\
\hline 6 & $\mathrm{O}_{2}+\mathrm{O}\left({ }^{3} \mathrm{P}\right)+\mathrm{N}_{2} \rightarrow \mathrm{O}_{3}+\mathrm{N}_{2}$ & $6.0 \cdot 10^{-34+++}$ & n.a. \\
\hline 7 & $\mathrm{O}\left({ }^{1} \mathrm{D}\right)+\mathrm{N}_{2} \rightarrow \mathrm{O}\left({ }^{3} \mathrm{P}\right)$ & $2.6 \cdot 10^{-11++}$ & n.a. \\
\hline 8 & $\mathrm{O}\left({ }^{1} \mathrm{D}\right)+\mathrm{H}_{2} \mathrm{O} \rightarrow 2 \mathrm{OH}$ & $2.2 \cdot 10^{-10++}$ & n.a. \\
\hline 9 & $\mathrm{Cl}+\mathrm{O}_{3} \rightarrow \mathrm{ClO}+\mathrm{O}_{2}$ & $1.2 \cdot 10^{-11++}$ & n.a. \\
\hline 10 & $\mathrm{Cl}+\mathrm{O}_{2}+\mathrm{N}_{2} \rightarrow \mathrm{ClOO}+\mathrm{N}_{2}$ & $2.7 \cdot 10^{-33+++}$ & n.a. \\
\hline 11 & $\mathrm{ClO}+\mathrm{O}\left({ }^{3} \mathrm{P}\right) \rightarrow \mathrm{O}_{2}+\mathrm{Cl}$ & $3.8 \cdot 10^{-11++}$ & n.a. \\
\hline 12 & $\mathrm{ClOO}+\mathrm{Cl} \rightarrow 2 \mathrm{ClO}$ & $1.2 \cdot 10^{-11++}$ & n.a. \\
\hline 13 & $\mathrm{ClOO}+\mathrm{N}_{2} \rightarrow \mathrm{Cl}+\mathrm{O}_{2}+\mathrm{N}_{2}$ & $6.2 \cdot 10^{-13++}$ & n.a. \\
\hline 14 & $\mathrm{ClOO}+\mathrm{O}\left({ }^{3} \mathrm{P}\right) \rightarrow \mathrm{O}_{2}+\mathrm{ClO}$ & $5.0 \cdot 10^{-11++}$ & n.a. \\
\hline 15 & $\mathrm{O}_{3}+\mathrm{H} \rightarrow \mathrm{HO}+\mathrm{O}_{2}$ & $2.9 \cdot 10^{-11++}$ & n.a. \\
\hline
\end{tabular}

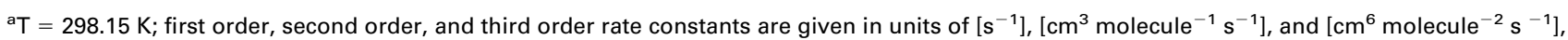
and are denoted as ${ }^{+},{ }^{++}$, and ${ }^{+++}$, respectively. Photolysis rate constants are calculated assuming a $10 \mathrm{~ns}$ laser pulse of $1 \mathrm{~mJ}$ energy at $\lambda=193$ $\mathrm{nm}$ and an irradiated area of $1 \mathrm{~cm}^{2}$. This corresponds to a photon density of $7.5 \cdot 10^{22}$ photon $\mathrm{cm}^{-2} \mathrm{~s}^{-1}$. The calculation of the rate constant for the PI lamp is not possible, due to the unknown photon density in the present set-up.

${ }^{b}$ Rate constants are taken from [19] and cross sectional data are taken from [6-13]. 
photolysis of $\mathrm{O}_{2}, \mathrm{H}_{2} \mathrm{O}$, and chlorinated solvents such as $\mathrm{CH}_{2} \mathrm{Cl}_{2}, \mathrm{CHCl}_{3}$, and $\mathrm{CCl}_{4}$, respectively. Each of these species potentially drives a comprehensive chemistry, which can be described using well known atmospheric processes. Table 1 summarizes the most relevant reactions that have to be considered when investigating mechanistic studies in an API source operating with VUV radiation as excitation source.

To assess representative radical concentrations within the present set-up, it is necessary to quantify the precursors $\mathrm{H}_{2} \mathrm{O}$ and $\mathrm{O}_{2}$ first. The latter is experimentally determined by measuring the ozone mixing ratio as a function of added known amounts of pure oxygen to the main gas flow. The oxygen is partly photodissociated upon irradiation with the $193 \mathrm{~nm}$ laser beam. This results in increasing concentrations of ozone primarily due the sequence

$$
\begin{aligned}
& \mathrm{O}_{2}+\mathrm{h} v \rightarrow 2 \mathrm{O}\left({ }^{3} \mathrm{P}\right) \\
& \mathrm{O}\left({ }^{3} \mathrm{P}\right)+\mathrm{O}_{2}+\mathrm{M} \rightarrow \mathrm{O}_{3}+\mathrm{M}
\end{aligned}
$$

(cf. reactions no $1 / 5 / 6 / 7$ in Table 1 ; at low water mixing ratios, the secondary photolysis of $\mathrm{O}_{3}$ results essentially in a null cycle). Plotting the measured ozone mixing ratio as a function of the added oxygen yields a straight line, which is extrapolated to the zero point of the ordinate yielding an $\mathrm{O}_{2}$ mixing ratio of $2.4 \%$, as shown in Figure 2. This procedure merely represents the wellknown analytical method of standard additions.

Routine operation of API sources, e.g., frequent solvent and sample change, frequent opening of the source enclosure for maintaining purposes, leads to highly variable water mixing ratios in the source enclosure. With respect to solvent purity, the range of dissolved $\mathrm{H}_{2} \mathrm{O}$ varies from 100 ppm in nonpolar solvents such as heptane or hexane, up to several percent in more polar solvents, e.g., $\mathrm{CH}_{3} \mathrm{OH}$ or $\mathrm{CH}_{3} \mathrm{CN}$. Since solvents are not used in the kinetic investigations, we have determined the water background concentration within the source, when all bulk gases are flowing. A flow controller at the exhaust line of the ion source is

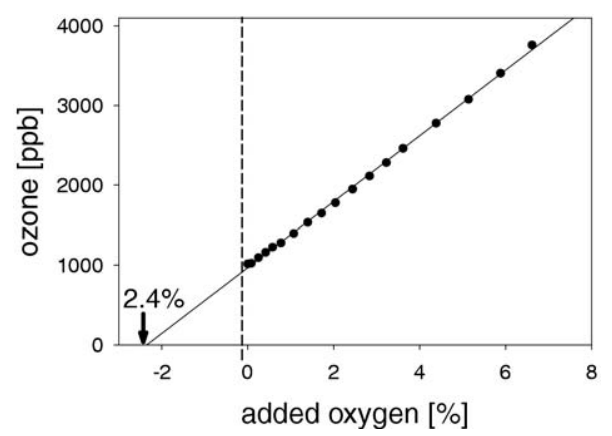

Figure 2. Standard addition method to determine the oxygen mixing ratio in the present API source. The ordinate intercept of $(-) 2.4 \%$ represents the source background $\mathrm{O}_{2}$ mixing ratio. Note that roughly $1 \mathrm{ppm} \mathrm{O}_{3}$ is generated under these conditions. used to maintain a constant gas flow. The exhaust gases are passed through a stripping coil, which is held at $-78^{\circ} \mathrm{C}$, leading to a quantitative condensation of gasphase water. By re-weighing the mass of the coil, the water background mixing ratio in the gas flow is determined to be roughly $100 \mathrm{ppmV}$. The water as well as the oxygen mixing ratios are determined after flushing the source for $20 \mathrm{~h}$ with heated nitrogen $\left(350^{\circ} \mathrm{C}\right)$, obtained from the nitrogen generator of the MS. The manufacturer states an initial $\mathrm{N}_{2}$ purity with less than $0.5 \%$ oxygen present. At the time of the experiments, the built-in cartridge was about 11 mo old. There was no information on the effectiveness of this cartridge with respect to reduction of other compounds such as $\mathrm{H}_{2} \mathrm{O}$. It is stressed though that the standard APPI/APCI ion source enclosure used here is a fairly open chamber, mainly due to the drain (cf. Figure 1, top). Hence, as soon as radical chemistry is turned on via photolysis, at least the reaction sequences sketched in Table 1 are initiated. This chemistry will become far more complex when further compounds are added. All of the radical species potentially affect the fate of analytes until they reach the collisions-free environment in the mass analyzer.

\section{Oxidation of the Pyrene Radical Cation}

Mass spectrometric product ion distributions. Upon vaporizing a $100 \mu \mathrm{L} \min ^{-1}$ flow of a $10 \mu \mathrm{M} A C N$ or $\mathrm{MeOH}$ solution of pyrene using the Apollo APPI source (cf. Figure 1, top), and switching on either the $193 \mathrm{~nm}$ laser or the PI lamp, three signals in addition to the radical cation of pyrene $\left(\mathrm{M}^{\bullet+}, m / z=202\right)$ at $m / z=217$, 218, and 219, i.e., $[\mathrm{M}+15]^{+},[\mathrm{M}+16]^{+}$, and $[\mathrm{M}+17]^{+}$ are detected. The chemical species leading to these signals are referred to as "oxygenated products" (see below). Identical results are obtained when gaseous pyrene is delivered directly at lower ppb mixing ratios, i.e., in the absence of solvents.

The experimental results obtained with the homebuilt setup (cf. Figure 1, bottom) are used to demonstrate that the observed additional signals are due to the formation of secondary products from the reaction of the pyrene radical cation $\mathrm{M}^{\bullet+}$ with neutral radicals. First, as shown in Figure 3, the $248 \mathrm{~nm}$ laser generated a strong pyrene signal recorded at $\mathrm{m} / \mathrm{z}=202$. In previous publications [3], we have shown that $248 \mathrm{~nm}$ APLI is selective towards the ionization of aromatic hydrocarbons and generates exclusively parent radical cations. In a second experiment, the $193 \mathrm{~nm}$ laser beam was switched on, resulting in a mass spectrum with the additional signals of $[\mathrm{M}+15]^{+},[\mathrm{M}+16]^{+}$, and $[\mathrm{M}+$ $17]^{+}$(Figure 3, top, b), while the sum of the signals at $m / z=202,217,218,219$, denoted here as total ion current (TIC), remains virtually constant. Hence, the signal intensity of $m / z=202$ decreases. Turning only the $248 \mathrm{~nm}$ laser off results in a nearly blank mass spectrum (Figure 3, top, c). This experiment clearly demonstrates: (1) the flow-tube setup allows the spatial separation of ion and neutral radical production; (2) 

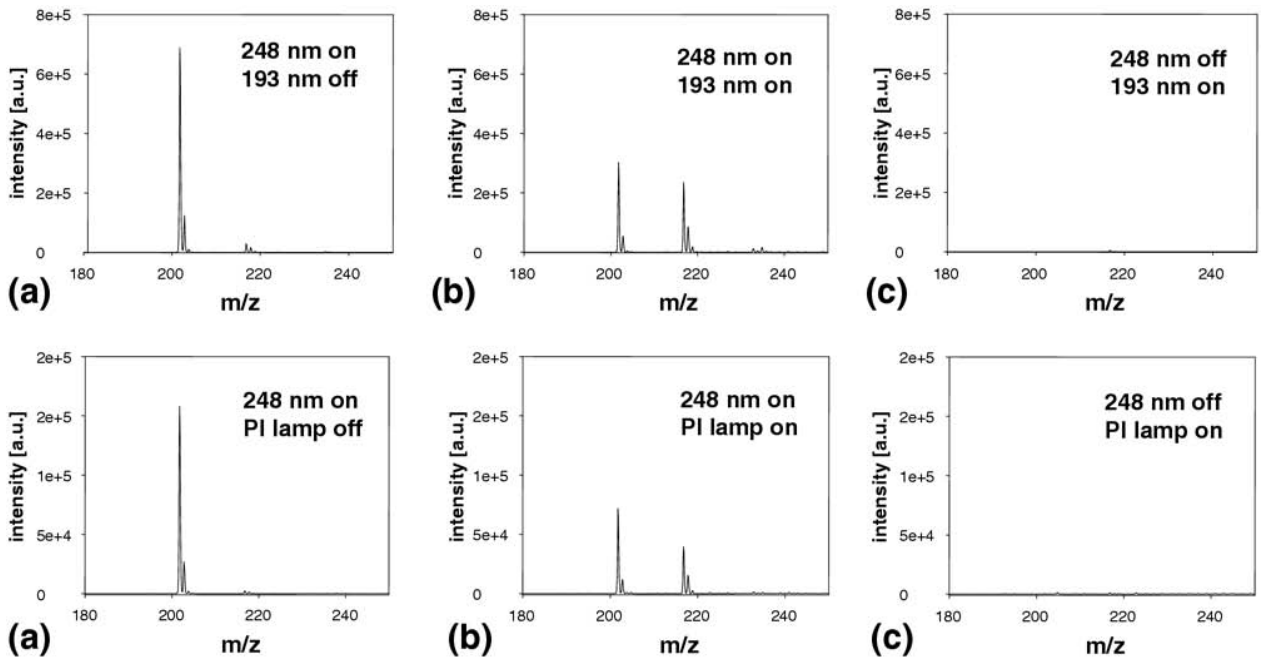

Figure 3. Mass spectra recorded upon irradiation of a nitrogen carrier gas flow in the presence of $\sim 6 \mathrm{ppbV}$ pyrene, $\sim 170 \mathrm{ppmV} \mathrm{CCl}_{4}, \sim 100 \mathrm{ppmV} \mathrm{O}_{2}$, and $\sim 200 \mathrm{ppmV} \mathrm{H}_{2} \mathrm{O}$. Top: (a) $248 \mathrm{~nm}$ laser on and $193 \mathrm{~nm}$ laser off; (b) both lasers on; (c) $248 \mathrm{~nm}$ laser off, $193 \mathrm{~nm}$ laser on. Bottom: (a) $248 \mathrm{~nm}$ laser on and VUV lamp off; (b) $248 \mathrm{~nm}$ laser on, VUV lamp on; (c) $248 \mathrm{~nm}$ laser off, VUV lamp on.

neutral radical formation is virtually absent at a wavelength of $248 \mathrm{~nm}$; (3) the additional signals generated with the $193 \mathrm{~nm}$ light are due to secondary products resulting from the reaction of neutral radicals with the radical cation. When the $193 \mathrm{~nm}$ laser is replaced with a Kr PI lamp operating at 124/116 nm (APPI) almost identical datasets are obtained (cf. Figure 3, bottom, a-c). We thus conclude that upon APPI at $124 \mathrm{~nm}$ a rich neutral radical chemistry is initiated, which may, depending on the experimental conditions, significantly impacting on the signal distribution in the resulting mass spectra (see below).

The relative and absolute intensity of the mass signals of the oxidation products is strongly changed by variation of the $\mathrm{O}_{2}, \mathrm{H}_{2} \mathrm{O}$ and $\mathrm{CH}_{n} \mathrm{Cl}_{4-n}(n=0-2)$ concentrations, respectively, while the TIC remains constant. Changing the ionizing laser position along the quartz tube main axis, i.e., changing the reaction time, also strongly affects the mass signal distribution up to the complete loss of $\mathrm{M}^{\cdot+}$. Collisionally induced dissociation (CID) of any of the three additional species results in loss of $m / z=28$ and 18 , assigned to $\mathrm{CO}$ and $\mathrm{H}_{2} \mathrm{O}$, respectively. This strongly suggests the addition of an oxygen atom to the radical cation in some way; this is the justification of denoting the additional signals as oxygenated products.

For simplification of the mechanistic studies, only the $193 \mathrm{~nm}$ laser in the flow tube setup (cf. Figure 1, bottom) was used as photolysis and ionization source and positioned between the exit of the glass tube and the entrance of the transfer capillary. With a carrier gas velocity of $46 \mathrm{~cm} \mathrm{~s}^{-1}$, a laser pulse repetition rate of 10 $\mathrm{Hz}$, and a laser beam width of $1 \mathrm{~cm}$ within the flow direction, a spatially well-defined volume ("package") is irradiated by the laser light only once. This ensures that (1) the radical cation generation is the initial process of all subsequent reactions, and (2) generated ozone is not photolyzed, yielding $\mathrm{O}\left({ }^{1} \mathrm{D}\right.$ ) atoms (cf. Table 1 , reaction no. 5), which would render further data interpretation much more difficult. In addition, the kinetic simulations are simplified, as specific neutral and ionic radical concentrations are generated as a "package" from the temporally and spatially well defined single laser pulse. The package travels toward the sampling orifice of the mass spectrometer. It is pointed out that the selected reaction time, defined by the laser position, and the initial concentrations of reactive reagents, defined by the total photon flux of one single laser pulse, determine the relative and absolute $\mathrm{M}^{\boldsymbol{*}+}$, $[\mathrm{M}+15]^{+},[\mathrm{M}+16]^{+}$, and $[\mathrm{M}+17]^{+}$signal intensities.

Computational data analysis-cases study. Experimental and theoretical investigations lead to two feasible reaction channels following the ionization step of the pyrene radical cation. One favors the direct addition of neutral radicals, such as $\mathrm{OH}$ and $\mathrm{O}\left({ }^{3} \mathrm{P}\right)$ to the aromatic ring system. The speculated second path is initiated by $\mathrm{H}$-abstraction from the pyrene skeleton and subsequent addition of $\mathrm{OH}, \mathrm{O}\left({ }^{3} \mathrm{P}\right)$, or even closed shell molecules, such as $\mathrm{H}_{2} \mathrm{O}$, to form the oxygenated products. These two cases are discussed in the following section; all molecular structures referenced with a "\#" are shown in Figure 4. all reactions referenced with a "no." are summarized in Table 2.

Case 1: Oxidation via direct addition of $\mathrm{O}\left({ }^{3} \mathrm{P}\right)$ and $\mathrm{OH}$ to $\mathrm{M}^{\bullet+}\left(\mathrm{M}^{\bullet+}+\mathrm{OH} \rightarrow[\mathrm{M}+\mathrm{OH}]^{+} \rightarrow \rightarrow\right.$ observed product ions, cf. Figure 5). Pyrene is a molecule of high symmetry, belonging to the point group $\mathrm{C} 1$. The three different possible positions of an electrophilic attack are shown in Structure \#1. The addition of neutral species to the pyrene radical cation is not favorable for closed shell molecules, e.g., $\mathrm{O}_{2}$ or $\mathrm{H}_{2} \mathrm{O}$, as reported earlier by Le Page et al. [15]. We fully confirm these results, since 

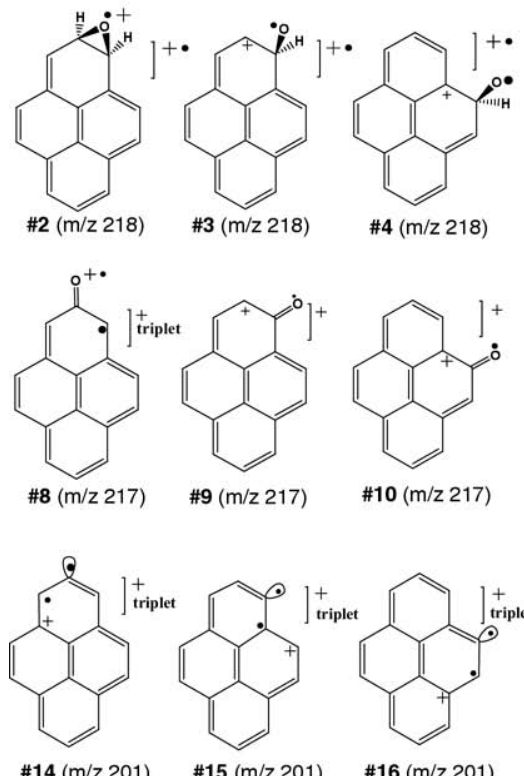

$\# 9(\mathrm{~m} / \mathrm{z} 217)$

$\# 10(\mathrm{~m} / \mathrm{z} 217)$
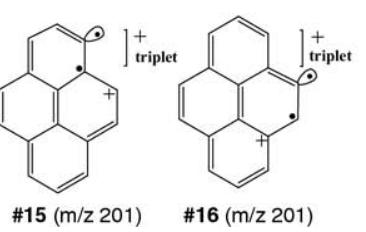
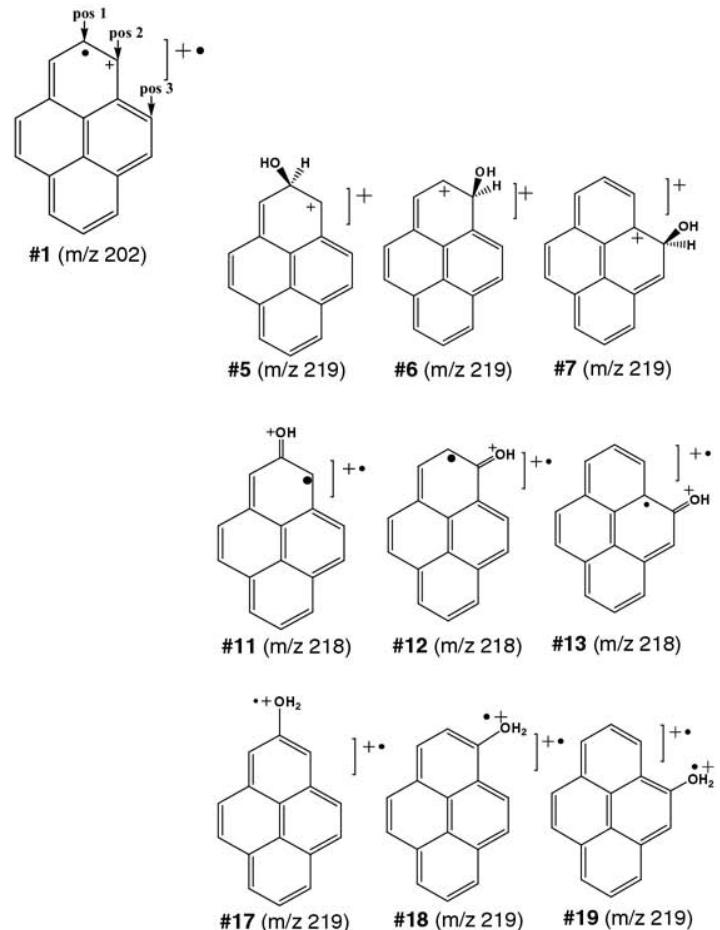

Figure 4. Possible structures within the oxidation pathways of the pyrenyl cation.

with $248 \mathrm{~nm}$ excitation virtually no other ions than $\mathrm{M}^{\bullet+}$, even in the presence of large quantities $\mathrm{H}_{2} \mathrm{O}$ and $\mathrm{O}_{2}$, are detected. However, the same authors showed that the addition of neutral radicals such as $\mathrm{O}\left({ }^{3} \mathrm{P}\right)$ or $\mathrm{H}$-atoms to the ionized ring system are fast reactions with bimolecular rate constants about $\mathrm{k} \approx$ $10^{-11}-10^{-10} \mathrm{~cm}^{3}$ molecule $\mathrm{s}^{-1}$. Wood et al. [27] also observed the rapid $\mathrm{OH}$ addition to ionized $\mathrm{C} 60$ fullerene, another highly condensed aromatic ring system. Our DFT calculations fully support this reaction pathway as well. The addition reactions of $\mathrm{O}\left({ }^{3} \mathrm{P}\right)$ or $\mathrm{OH}$ to the pyrene radical cation (Reactions no. 1 and no. 2) leading to Structures \#2 - \#4 and \#5 - \#7, are calculated to be exergonic by $\Delta \mathrm{G}_{\mathrm{R}}=-2.00$ to $-1.09 \mathrm{eV}$ and -1.52 to $-0.78 \mathrm{eV}$, respectively. The subsequent step in this reaction path is speculated to be $\mathrm{H}$-atom abstraction

Table 2. Computed $\Delta \mathrm{G}_{\mathrm{R}}$ values [eV] for the examined reactions

\begin{tabular}{|c|c|c|c|c|c|}
\hline No. & $\begin{array}{l}\text { Reactant structure of } \\
\text { the pyrene system }{ }^{\text {a }}\end{array}$ & Other reagents & $\begin{array}{l}\text { Product structure of } \\
\text { the pyrene system }^{\text {a }}\end{array}$ & Other products & $\begin{array}{l}\text { Gibbs free energy of } \\
\text { reaction } \Delta G_{R}[e V]^{b}\end{array}$ \\
\hline 1 & $\# 1$ & $\mathrm{O}\left({ }^{3} \mathrm{P}\right)$ & $\# 2 / \# 3 / \# 4$ & - & $-2.00 /-1.58 /-1.09$ \\
\hline 2 & $\# 1$ & $\mathrm{OH}$ & \#5/\#6/\#7 & - & $-0.78 /-1.52 /-1.04$ \\
\hline 3 & \#2/\#3/\#4 & - & \#8/\#9/\#10 & $\mathrm{H}$ & $1.75 / 0.44 / 0.40$ \\
\hline 4 & $\# 5 / \# 6 / \# 7$ & - & $\# 11 / \# 12 / \# 13$ & $\mathrm{H}$ & $1.14 / 1.69 / 1.22$ \\
\hline 5 & $\# 5 / \# 6 / \# 7$ & - & \#2/\#3/\#4 & $\mathrm{H}$ & $2.94 / 4.09 / 4.10$ \\
\hline 6 & $\# 11 / \# 12 / \# 13$ & - & \#8/\#9/\#10 & $\mathrm{H}$ & $3.56 / 2.84 / 3.28$ \\
\hline 7 & \#1 & - & \#14/\#15/\#16 & $\mathrm{H}$ & $4.57 / 4.48 / 4.51$ \\
\hline 8 & \#14/\#15/\#16 & $\mathrm{O}\left({ }^{3} \mathrm{P}\right)$ & \#8/\#9/\#10 & - & $-4.82 /-5.62 /-5.21$ \\
\hline 9 & \#14/\#15/\#16 & $\mathrm{OH}$ & \#11/\#12/\#13 & - & $-4.22 /-4.30 /-4.33$ \\
\hline 10 & $\# 14 / \# 15 / \# 16$ & $\mathrm{H}_{2} \mathrm{O}$ & \#17/\#18/\#19 & - & $-0.71 /-0.57 /-0.56$ \\
\hline 11 & \#17/\#18/\#19 & - & \#11/\#12/\#13 & $\mathrm{H}$ & 1.13/0.91/0.87 \\
\hline 12 & - & $\mathrm{H}+\mathrm{OH}$ & - & $\mathrm{H}_{2} \mathrm{O}$ & -4.64 \\
\hline 13 & - & $\mathrm{H}+\mathrm{O}\left({ }^{3} \mathrm{P}\right)$ & - & $\mathrm{OH}$ & -4.16 \\
\hline 14 & - & $\mathrm{H}+\mathrm{H}$ & - & $\mathrm{H}_{2}$ & -4.24 \\
\hline 15 & - & $\mathrm{H}+\mathrm{O}_{3}$ & - & $\mathrm{OH}+\mathrm{O}_{2}$ & -3.91 \\
\hline 16 & - & $\mathrm{H}+\mathrm{O}_{2}$ & - & $\mathrm{HO}_{2}$ & -1.84 \\
\hline 17 & - & $\mathrm{H}+\mathrm{Cl}$ & - & $\mathrm{HCl}$ & -4.03 \\
\hline 18 & - & $\mathrm{H}+\mathrm{ClO}$ & - & $\mathrm{HOCl}$ & -3.69 \\
\hline 19 & - & $\mathrm{H}+\mathrm{ClOO}$ & - & $\mathrm{ClO}+\mathrm{OH}$ & -1.67 \\
\hline
\end{tabular}

apyrene structures are numbered as shown in Figure 4.

bIn the case of possible singlet and triplet structures, only the most stable one is listed, as denoted in Figures 5 and 6. 


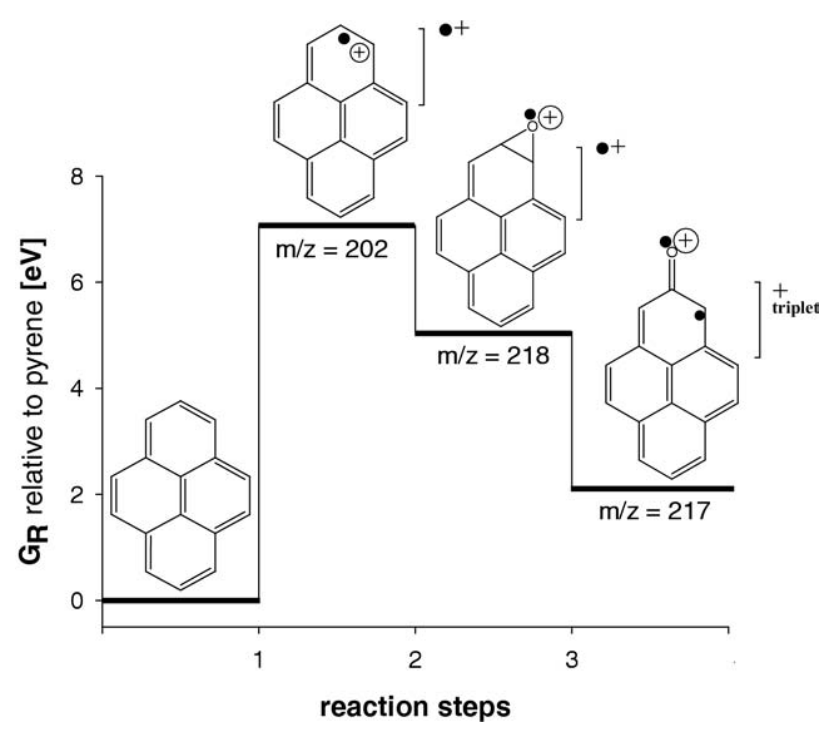

Figure 5. Reaction steps: (1) $\mathrm{M} \rightarrow \mathrm{M}^{\bullet+}$, (2) $\mathrm{M}^{\bullet+}+\mathrm{O} \rightarrow[\mathrm{M}+$ $\mathrm{O}]^{\bullet+}$, (3) $[\mathrm{M}+\mathrm{O}]^{\bullet+}+\mathrm{OH} \rightarrow[\mathrm{M}-\mathrm{H}+\mathrm{O}]^{+}+\mathrm{H}_{2} \mathrm{O} \cdot \Delta \mathrm{G}_{\mathrm{R}}=\mathrm{G}_{\mathrm{R}}$ relative to pyrene $(\mathrm{g})$.

from the oxygenated pyrene, e.g., by $\mathrm{OH}$ radicals. $\mathrm{OH}$ radicals are always present in APPI due to photolysis of $\mathrm{H}_{2} \mathrm{O}$. For Structures \#2 - \#4 transformed to structures $\# 8-\# 10$, Gibbs free energies range from $\Delta G_{R}=-4.24$ to $-2.89 \mathrm{eV}$ (no. 3 combined with no. 12). So far, the analogy to the well-described nucleophilic aromatic substitution reaction type is striking. In the cases of Structures \#5 - \#7, two H-atom abstraction channels by $\mathrm{OH}$ radicals are feasible (Reaction no. 4/no. 5 combined with, e.g., no. 12). First, according to the nucleophilic aromatic substitution scheme, removal of the H-atom from the carbon skeleton leads to Structures \#11 - \#13 $\left(\Delta \mathrm{G}_{\mathrm{R}}=-3.50\right.$ to $\left.-2.95 \mathrm{eV}\right)$. The second channel is the $\mathrm{H}$-atom abstraction from the hydroxyl group, yielding the same products as with $\mathrm{O}\left({ }^{3} \mathrm{P}\right)$ addition to the pyrene radical cation ( $\# 2-\# 4 ; \Delta \mathrm{G}_{\mathrm{R}}=-1.70 \mathrm{eV}$ to $-0.54 \mathrm{eV}$ ). The latter compounds can repeatedly react with neutral radicals, as shown before, to yield products with Structures \#8 - \#10. The products from reaction no. 4 (\#11 \#13) can further react with neutral radicals via H-atom abstraction from the hydroxyl group to form the Products \#8 - \#10 $\left(\Delta \mathrm{G}_{\mathrm{R}}=-1.80 \mathrm{eV}\right.$ to $-1.08 \mathrm{eV}$; no 6 . combined with no. 12). Obviously, all intermediates are eventually converted to the most stable species with $\mathrm{m} / \mathrm{z}$ $=217$. This trend is very well supported by our experimental data. The signal at $\mathrm{m} / \mathrm{z}=217$ increases with increasing neutral radical concentration and/or with increasing reaction time. It is stressed that the neutral radical concentrations exceed the parent ion concentration by orders of magnitude.

Case 2: Oxidation via the pyrenyl cation $[\mathrm{M}-\mathrm{H}]^{+}$after initial H-atom abstraction from $\mathrm{M}^{\bullet+}\left(\mathrm{M}^{\bullet+}+\mathrm{OH} \rightarrow[\mathrm{M}-\right.$ $\mathrm{H}^{+}+\mathrm{H}_{2} \mathrm{O} \rightarrow \rightarrow$ observed product ions, cf. Figure 6). The $\mathrm{C}-\mathrm{H}$ bond dissociation enthalpy is rather high, experimentally determined to be $4.6 \mathrm{eV}[28,29]$ and calculated to be $\Delta \mathrm{H}_{\mathrm{d}(\mathrm{C}-\mathrm{H})}^{\circ}=4.93 \mathrm{eV}, 4.84 \mathrm{eV}$, and $4.88 \mathrm{eV}$ for the positions 1,2 , and 3 , respectively. Thus, reactions leading to the pyrenyl cation (\#14 - \#16) in its triplet state as the most stable conformation are rather limited.

It can be speculated that the available maximum excess energy $\left(E_{\text {excess max }}\right)$, i.e., the difference of the total energy of the two absorbed photons $\left(E_{\text {total }}\right)$ and the ionization energy (IE $=7.41 \mathrm{eV}[30]$ given by eq 1

$$
\mathrm{E}_{\text {excess max }}=\mathrm{E}_{\text {total }}-\mathrm{IE}
$$

is sufficient to initiate unimolecular fragmentation reactions of the types

$$
\begin{aligned}
& \mathrm{M}^{+} \rightarrow[\mathrm{M}-\mathrm{H}]^{+}+\mathrm{H} \\
& \mathrm{M}^{+} \rightarrow[\mathrm{M}-2 \mathrm{H}]^{+}+2 \mathrm{H} / \mathrm{H}_{2}
\end{aligned}
$$

Following two-photon ionization at $248 \mathrm{~nm}$ (excess energy $=2.6 \mathrm{eV}$ ) this pathway is immediately excluded. Absorption of two $193 \mathrm{~nm}$ photons contributes an excess energy of $5.4 \mathrm{eV}$ to the pyrene radical cation, which appears to be sufficiently high. However, Ling et al. determined the appearance energy $(\mathrm{AE})$ of the pyrenyl cation $[\mathrm{M}-\mathrm{H}]^{+}$with time-resolved photoionization mass spectrometry (TPIS) to be $15.2 \mathrm{eV}$ [28]. Hence, an effective excess energy of at least $7.8 \mathrm{eV}$ is required for the formation of the pyrenyl cation and thus unimolecular decomposition after $193 \mathrm{~nm}(1+1)$ REMPI is excluded as well. More importantly, it is highly unlikely that the parent ion is generated by direct two photon absorption. As discussed below, ultra-fast relaxation of the intermediately pumped $S_{4}$ state into the $S_{1}$ manifold strongly suggests that the parent ion is carrying an excess energy far below $(6.3+$ 6.3) $\mathrm{eV}$.

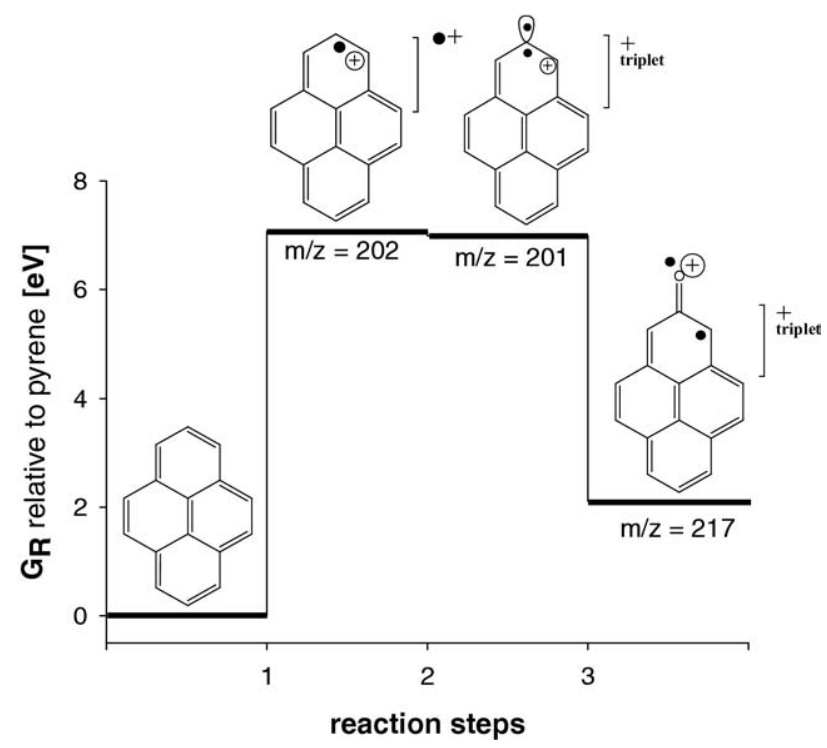

Figure 6. Reaction steps: (1) $\mathrm{M} \rightarrow \mathrm{M}^{\bullet+}$, (2) $\mathrm{M}^{\bullet+}+\mathrm{OH} \rightarrow[\mathrm{M}-$ $\mathrm{H}]^{+}+\mathrm{H}_{2} \mathrm{O}$, (3) $[\mathrm{M}-\mathrm{H}]^{+}+\mathrm{O} \rightarrow[\mathrm{M}-\mathrm{H}+\mathrm{O}]^{+} . \Delta \mathrm{G}_{\mathrm{R}}=\mathrm{G}_{\mathrm{R}}$ relative to pyrene $(\mathrm{g})$. 
Among the various neutral radical species typically generated in the ion source, only the hydroxyl radical seems to be able to abstract an $\mathrm{H}$-atom of the pyrene radical cation carbon skeleton. Enthalpy release and the Gibbs free-energy for the formation of the $\mathrm{H}-\mathrm{OH}$ bond accounts for $\Delta \mathrm{H}_{\mathrm{f}(\mathrm{H}-\mathrm{OH})}=-4.96 \mathrm{eV}$ (literature value: $-5.11 \mathrm{eV}$ [31] and $\Delta \mathrm{G}_{\mathrm{R}}=-4.64 \mathrm{eV}$ (literature value: $-4.83 \mathrm{eV}$ [19], respectively. The Gibbs free-energy of the $\mathrm{C}-\mathrm{H}$ dissociation Reaction no. 7 is calculated to be in the range of $\Delta \mathrm{G}_{\mathrm{R}}=4.48 \mathrm{eV}$ and $4.57 \mathrm{eV}$. Once the pyrenyl cation is formed it shows high reactivity towards neutral radical species and even closed shell molecules such as $\mathrm{H}_{2} \mathrm{O}[15,29,32]$. The addition of $\mathrm{O}\left({ }^{3} \mathrm{P}\right)$ and $\mathrm{OH}$ (no. 8/no. 9) lead to Structures \#8 - \#10 and \#11 - \#13 with $\Delta \mathrm{G}_{\mathrm{R}}$ between $-5.62 \mathrm{eV}$ and $-4.82 \mathrm{eV}$, and $\Delta \mathrm{G}_{\mathrm{R}}$ in the range of $-4.33 \mathrm{eV}$ and $-4.22 \mathrm{eV}$, respectively. Henceforward, the sequence proceeds via Reaction no. 6 as described in the preceding section of the direct addition channel. The addition of $\mathrm{H}_{2} \mathrm{O}$ to the pyrenyl cation forms Structures \#17 - \#18 with $\Delta \mathrm{G}_{\mathrm{R}}$ between $-0.71 \mathrm{eV}$ and $-0.56 \mathrm{eV}$. The subsequent removal of the hydroxyl $\mathrm{H}$-atoms leads to the most stable phenoxy type species $\# 8-\# 10(\mathrm{~m} / \mathrm{z}=217$; no. $11 /$ no. 6$)$, again in analogy to the direct addition channel. Another possible route is the addition of molecular oxygen to the pyrenyl cation, leading to a peroxy radical $(m / z=233)$. This mass is recorded as minor signal $(\sim 0.2 \%$ of the TIC), when 420 ppm $\mathrm{H}_{2} \mathrm{O}$ and $0.7 \% \mathrm{O}_{2}$ are present. However, this signal could also be attributed to the 2-fold $\mathrm{OH}$ or $\mathrm{O}\left({ }^{3} \mathrm{P}\right)$ addition with subsequent $\mathrm{H}$-atom abstraction. If the reaction proceeds via peroxy radical intermediates then the corresponding signal should be rather low, as observed: (1) very small peroxy radical population is formed, due to the comparably low third order rate constant(s) or simply due to the missing pyrenyl cation as a precursor, (2) the subsequent reaction of forming a hydroperoxy radical, followed by $\mathrm{O}-\mathrm{OH}$ bond cleavage to release an $\mathrm{OH}$ radical and the most stable phenoxy type species \#8 - \#10 would lead to a rapid degradation of the peroxy radical cation concentration.

Consequently, also the pyrenyl cation reaction channel favors phenoxy-type end-products $(m / z=217)$ with increasing radical concentration and/or with increasing reaction time.

Though $[\mathrm{M}-\mathrm{H}]^{+}$species are far more reactive than the corresponding $\mathrm{M}^{\bullet+}$ precursors, the major reaction pathway is attributed to the direct addition of $\mathrm{OH}$ and $\mathrm{O}\left({ }^{3} \mathrm{P}\right)$. This is rationalized in the following manner: (1) generation of pyrenyl cations is unlikely, mainly due to the high dissociation enthalpy of the $\mathrm{C}-\mathrm{H}$ bond, (2) the corresponding reaction of the neutral atmospheric degradation of aromatic compounds with $\mathrm{OH}$ proceeds up to $90 \%$ via the $\mathrm{OH}$ addition channel [33], and (3) the signal recorded at $m / z=201$, attributed to $[\mathrm{M}-\mathrm{H}]^{+}$, has a very low abundance. The latter argument is of course also in accord with the high reactivity of $[\mathrm{M}-\mathrm{H}]^{+}$.

In conclusion, the $\mathrm{OH}$ radical addition channel to the charged aromatic ring system is much more likely to be responsible for the efficient oxidation of primarily formed radical cations. In the following section on kinetic simulations, the oxidation pathway via the pyrenyl cation is thus not considered further.

Kinetic data analysis. Further elucidation of feasible oxidation mechanisms is carried out by comparison of experimentally recorded mass spectra with results from kinetic simulations. In these experiments, the $193 \mathrm{~nm}$ laser is running with a repetition rate of $10 \mathrm{~Hz}$ (see above) and positioned 0.5 to $1.5 \mathrm{~cm}$ upstream of the entrance of the MS inlet capillary (cf. Figure 1, bottom). The abundances of major signals in the recorded mass spectrum are summarized in Table 3 . The summed peak areas of the oxygenated products account for $92 \%$ of the $\mathrm{M}^{\bullet+}$ peak area. Assuming that the addition channel is dominating, $\mathrm{O}\left({ }^{3} \mathrm{P}\right)$ and $\mathrm{OH}$ attack could potentially lead to primary oxygenated products with $\mathrm{m} / \mathrm{z}=218$ and 219 , respectively.

Calculation of the total reaction time. As mentioned previously, the total reaction time depends on the laser position and the coaxial gas flow velocity, in this case the average of the laminar profile velocity distribution within the reaction tube. However, since local pressures and, thus, collision rates within the MS sample capillary are rather high, the velocity profile inside the capillary has to be considered. The average transport velocity within the laminar flow in the reaction tube of setup 2 is $46 \mathrm{~cm} \mathrm{~s}^{-1}$ (cf. Experimental section). The average reaction time for primary ions and neutral radicals generated in the center of the laser irradiated volume, respectively, is thus about $21 \mathrm{~ms}$ before entering the MS sample capillary.

Under the present conditions, i.e., upstream stagnation pressure $p_{0}=970$ mbar, first MS pumping stage pressure $\mathrm{p}_{1}=4 \mathrm{mbar}$, total flow $\mathrm{Q}=1.4 \mathrm{~L} / \mathrm{min}$, capillary diameter $=0.6 \mathrm{~mm}$, and capillary length $=18$ $\mathrm{cm}$, choked flow occurs. The minimum or critical capillary pressure is reached at the capillary exit, where the gas velocity reaches sonic speed. This critical pressure is calculated using eq 2 to be roughly 200 mbar [34]. Within the capillary, the gas velocity increases significantly with the decreasing pressure. The pressure profile of an ideal compressible fluid flowing with friction through a tube is described by eq 3 [35]. Assuming that the bulk gas temperature is the same as the wall

Table 3. Major peak abundances in a mass spectrum recorded upon irradiating a flow of $\mathrm{N}_{2}$ at 1 bar with 420 ppm $\mathrm{H}_{2} \mathrm{O}, 0.7 \%$ $\mathrm{O}_{2}$, and 6 ppb pyrene present

\begin{tabular}{lcc}
\hline$m / z$ & Assigned structures & \\
\hline \hline 202 & \multicolumn{1}{c}{$\# 1$} & Rel. peak area [\%] $^{\mathrm{b}}$ \\
217 & $\# 8-\# 10$ & 100 \\
218 & $\# 2-\# 4$ and \#11-\#13 & 70.4 \\
219 & $\# 5-\# 7$ & 18.0 \\
\hline
\end{tabular}

${ }^{\mathrm{a} c f .}$ Figure 4.

${ }^{\text {b }}$ Relative to the pyrene radical cation $\mathrm{M}^{\bullet+}$. 
temperature, the corresponding velocity distribution (eq 4) follows directly from eq 3 [35].

$$
\begin{aligned}
& p_{2}^{*}=4.51 \cdot\left(\frac{d^{3} \cdot p_{0}^{2}}{2 L}\right)^{\frac{4}{7}} \cdot d^{-1} \\
& p_{x}=\left(1-\left(1-P^{2}\right) \cdot \frac{x}{L}\right)^{\frac{1}{2}} \cdot p_{0} \\
& v_{x}=\left(1-\left(1-P^{2}\right) \cdot \frac{x}{L}\right)^{\frac{1}{2}} \cdot v_{e}
\end{aligned}
$$

$\left(\mathrm{p}_{0}=\right.$ upstream stagnation pressure [mbar], $\mathrm{p}_{2}=$ first pumping stage pressure $[\mathrm{mbar}], \mathrm{p}_{2}^{*}=$ critical capillary exit pressure $[\mathrm{mbar}], \mathrm{d}=$ capillary diameter $[\mathrm{cm}], \mathrm{L}=$ capillary length $[\mathrm{cm}], \mathrm{P}=\mathrm{p}_{2} / \mathrm{p}_{0}, \mathrm{v}_{\mathrm{x}}=$ gas velocity at position $x[\mathrm{~cm} / \mathrm{s}], \mathrm{v}_{\mathrm{e}}=$ gas velocity at the capillary entrance $[\mathrm{cm} / \mathrm{s}], \mathrm{x}=$ coordinate of the capillary main axis).

Integration of eq 4 from 0 to $18 \mathrm{~cm}$ yields a total transit time of $1.6 \mathrm{~ms}$. We will give a thorough account of the flow conditions and the ion transport efficiency of the MS sample capillary in an upcoming publication [36]. Here we just note that all the assumptions above and calculations are very well supported by experimental data, particularly the critical capillary exit pressure and the total transit time.

We are thus taking a total of $23 \mathrm{~ms}(21 \mathrm{~ms}$ in the flow tube and $2 \mathrm{~ms}$ in the capillary) as the average reaction time. Note that the mean free path is on the same order of magnitude throughout the whole pathway from the point of ion/radical production to the exit of the MS sample capillary. Downstream of the capillary exit it is reasonably to assume that a super sonic jet expansion forms [37] and that after passing the freeze in plane (roughly 10 orifice diameters downstream of the capillary exit) no further collisions and thus alterations to the ion population and to the peak abundances in the recorded mass spectra occur.

Estimation of the pyrene radical cation concentration. Computational simulation of the resulting charged product distribution recorded after a reaction time of $23 \mathrm{~ms}$ requires an estimate of the initial pyrene radical cation concentration. The radical cation concentration $\left[\mathrm{M}^{\bullet+}\right]$ generated within one laser pulse via a $(1+1)$ REMPI process is calculated using eq 5 :

$$
\left[\mathrm{M}^{\cdot+}\right]=[\mathrm{M}]-[\mathrm{M}] \cdot \exp (-\mathrm{kt})
$$

$\left(\mathrm{k}=\right.$ first-order rate constant of formation $\left[\mathrm{s}^{-1}\right],[\mathrm{M}]=$ initial pyrene concentration [molecule $\mathrm{cm}^{-3}$ ], and $\mathrm{t}=$ laser pulse duration $\left[\mathrm{s}^{-1}\right]$. $\mathrm{k}$ is obtained from the equation

$$
\mathrm{k}=\sigma \cdot \Phi^{2} \cdot \varphi_{1} \cdot \varphi_{2}
$$

$(\sigma=$ absorption cross section of the overall $(1+1)$ REMPI process $\left[\mathrm{cm}^{4} \mathrm{~s}\right.$ molecule $\left.{ }^{-2}\right] ; \Phi=$ photon flux [photon $\mathrm{s}^{-1} \mathrm{~cm}^{-2}$ ]; $\varphi_{1,2}=$ quantum yield for each step of the two absorption processes [molecule photon ${ }^{-1}$ ]).

The overall absorption cross section $\sigma$ is derived from the equation

$$
\sigma=\sigma_{1} \cdot \sigma_{2} \cdot \tau
$$

$\left(\sigma_{1,2}=\right.$ single step absorption cross section of each excitation process [ $\mathrm{cm}^{2}$ molecule]; $\tau=$ lifetime of the intermediate resonant state $[\mathrm{s}]$ ).

The excitation of pyrene at $193 \mathrm{~nm}$ results in initial population of the $S_{4}$ state, which relaxes to the $S_{1}$ manifold on the ps time-scale [38]. The $S_{1}$ state has an estimated lifetime of $\tau \approx 100 \mathrm{~ns}$ [38-43], which is 10 times larger than the laser pulse width. Thus, the transition into the ionization region originates from the $S_{1}$ manifold. The subsequent single step absorption cross sections are assumed to be identical, with $\sigma_{1}=\sigma_{2}=1.7 \times$ $10^{-17} \mathrm{~cm}^{2}$ [44]. The quantum yields for both absorption steps are assumed to be $\varphi_{1}=\varphi_{2}=1$ molecule photon ${ }^{-1}$, the photon flux is $\Phi=6.0 \times 10^{22}$ photon s $\mathrm{sm}^{-2}$, and the laser pulse duration is $\mathrm{t}=10 \mathrm{~ns}$. Therefore, an initial pyrene concentration of $6 \mathrm{ppbV}$ leads to a pyrene radical cation concentration of $\left[\mathrm{M}^{\bullet+}\right] \approx 1.5 \times 10^{8}$ molecule $\mathrm{cm}^{-3}$ (about $5 \mathrm{pptV}$ ) generated within one laser pulse. Since the neutral radical concentrations are at least one order of magnitude higher, all reactions proceed in pseudo first-order with respect to the charged species. It follows that the product peak abundance distribution relative to the abundance of $\mathrm{M}^{\bullet+}$ is independent of the initial pyrene radical cation concentration and is controlled by the concentration of the neutral radicals.

Impact of $\mathrm{O}_{2}, \mathrm{O}\left({ }^{3} \mathrm{P}\right)$, and $\mathrm{O}_{3}$ on the ion signal distribution. The initial $\mathrm{O}\left({ }^{3} \mathrm{P}\right)$ mixing ratio is calculated as $3.1 \mathrm{ppb}$ when $0.7 \%$ oxygen is present in the source enclosure. Applying a rate constant of $\mathrm{k}=9.5 \times 10^{-11} \mathrm{~cm}^{3}$ molecule $^{-1}$ $\mathrm{s}^{-1}$ [15] for the reaction of $\mathrm{O}\left({ }^{3} \mathrm{P}\right)$ with pyrene radical cations, $16 \%$ of the latter are converted into the oxygen adduct (\#2 - \#4) within $23 \mathrm{~ms}$ reaction time. Hence, the hypothetical outcome of the mass spectrum would exhibit two signals, $\mathrm{M}^{\cdot+}$ and $[\mathrm{M}+16]^{+}$, with a ratio of about 100:16. However, due to the high mixing ratio of $\mathrm{O}_{2}$ the competing ozone formation reaction (no. 6, Table 1) is proceeding much faster, nearly quantitatively converting the entire $\mathrm{O}\left({ }^{3} \mathrm{P}\right)$ population into $\mathrm{O}_{3}$. Ozone, however, is a rather inert species in the present environment towards ionized aromatic species, as shown by Mendes et al. [45]. Since the laser pulse irradiates the spatially defined "package" only once, photolysis of ozone (no. 5, Table 1) and, thus, formation of $\mathrm{O}\left({ }^{1} \mathrm{D}\right)$ is excluded. Taking the ozone generation reaction into account, only $0.3 \%$ of the initial pyrene radical cations would be converted to the oxygen adducts \#2 - \#4 
within $24 \mathrm{~ms}$ reaction time and two peaks with ratios of $\mathrm{M}^{\bullet+}:[\mathrm{M}+16]^{+}=100: 0.3$ should occur in the corresponding hypothetical mass spectrum. The experimental results though do show a strong signal at $[\mathrm{M}+16]^{+}$ and, thus, reaction of $\mathrm{O}\left({ }^{3} \mathrm{P}\right)$ directly with primary radical cations cannot account for the experimentally observed ion population.

Impact of $\mathrm{H}_{2} \mathrm{O}, \mathrm{OH}$, and $\mathrm{H}$ on the ion distribution. As previously mentioned, no reactivity of the pyrene radical cation towards closed shell molecules such as $\mathrm{H}_{2} \mathrm{O}$ was observed [15]. This is in very good agreement with the present experimental results. However, photodissociation of $\mathrm{H}_{2} \mathrm{O}$ with the $193 \mathrm{~nm}$ laser pulse results in $\mathrm{H}$ atom and $\mathrm{OH}$ radical mixing ratios of $0.6 \mathrm{ppbV}$, respectively. Unfortunately, no rate constant for the addition reaction of $\mathrm{OH}$ to $\mathrm{M}^{\bullet+}$ is available. Atkinson et al. reported the rate constant for the analogue neutral reaction,

$$
\text { Pyrene }+\mathrm{OH} \rightarrow[\text { Pyrene }+\mathrm{OH}]
$$

to be $\mathrm{k}=5 \times 10^{-11} \mathrm{~cm}^{3}$ molecule ${ }^{-1} \mathrm{~s}^{-1}$ [46]. Frequently, the rate constants for the same type of reaction can rise by one or two orders of magnitude if one of the reactants is charged. For example, the $\mathrm{O}\left({ }^{3} \mathrm{P}\right)$ addition to naphthalene is $\sim 90$ times faster when the aromatic system carries a positive charge [47, 48].

If we assume a rate constant of $\mathrm{k}=1.9 \times 10^{-9} \mathrm{~cm}^{3}$ molecule ${ }^{-1} \mathrm{~s}^{-1}$ for the $\mathrm{OH}$ addition reaction to the pyrene radical cation, a signal distribution of $\mathrm{M}^{\bullet+}:[\mathrm{M}+\mathrm{OH}]^{+}=$ 100:95 is calculated for a reaction time of $23 \mathrm{~ms}$. Hence, a hypothetical mass spectrum would exhibit two signals, $\mathrm{m} / \mathrm{z} 202$ and 219 with comparable intensities. This is in very good agreement with our experimental observations with respect to the signal intensity of the sum of the oxygenated products, i.e., $[\mathrm{M}+15]^{+},[\mathrm{M}+16]^{+}$, and $[\mathrm{M}+17]^{+}$, relative to $\mathrm{M}^{\bullet+}$. The already discussed consecutive $\mathrm{H}$-atom abstractions leading to the final product distribution (cf. Table 3 ) are driven by reactions with $\mathrm{O}_{2}, \mathrm{O}_{3}, \mathrm{H}$, and $\mathrm{OH}$. All of these species react with $\mathrm{H}$-atoms exergonic enough to compensate most of the positive Gibb's free energies of dissociation for the $\mathrm{C}-\mathrm{H}$ and $\mathrm{O}-\mathrm{H}$ bond cleavages (cf. Table 2, no. 12/14/15/16 compared with no. 3/4/5/6). In conclusion, the $\mathrm{OH}$ addition to the pyrene radical cation is determined to be the first step, whereas the subsequent H-atom abstractions are straightforward, since all of the mentioned reactants are present in large quantities. This reasoning is supported by experimental data: upon increasing any radical concentration, the relative distribution among the oxygenated products always leads to dominating signals at $m / z=217$, corresponding with formation of the most stable phenoxy type product (Structures \#8 \#10 in Figure 4).

The remaining species that has to be considered in this context is the $\mathrm{H}$ atom. Le Page et al. [15] determined the rate constant of the addition reaction $\mathrm{M}^{\bullet+}+\mathrm{H}$ to form $[\mathrm{M}+\mathrm{H}]^{+}$as $\mathrm{k}=1.4 \cdot 10^{-10} \mathrm{~cm}^{3}$ molecule ${ }^{-1} \mathrm{~s}^{-1}$. Thermochemical data as well support this reaction with Gibbs free energies of $\Delta \mathrm{G}_{\mathrm{R}}=-1.71 \mathrm{eV},-2.33 \mathrm{eV}$, and -1.88 $\mathrm{eV}$ for position 1, 2, and 3, respectively. Applying the above rate constant would result in a relative ratio of $\mathrm{M}^{\bullet+}:[\mathrm{M}+\mathrm{H}]^{+}=100: 5$ with 23 ms reaction time. The additional consideration of the isotopic ratios leads to a hypothetical outcome of the mass spectrum with a ratio of $m / z$ 202:203 = 100:22; the experimentally observed ratio is 100:17. The present results are thus ambiguous. However, the back reaction of $\left[\mathrm{M}+\mathrm{H}^{+}\right.$with $\mathrm{O}_{3}, \mathrm{OH}$, and also $\mathrm{H}$ is exergonic. It appears to be unlikely that under the prevailing conditions any significant population of $[\mathrm{M}+\mathrm{H}]^{+}$is thus produced.

Impact of $\mathrm{Cl}, \mathrm{ClO}$, and $\mathrm{ClOO}$ on the ion distribution. In the kinetic investigations described so far, chlorinated reactants were absent. Upon introducing chlorinated species, the ion chemistry becomes increasingly complex. The product analysis is thus rendered even more difficult. However, the impact of the presence of chlorinated species on the relative ion distribution is noteworthy. Feeding $\mathrm{Cl}$ atoms, e.g., via photolysis of $\mathrm{CH}_{\mathrm{n}} \mathrm{Cl}_{4-\mathrm{n}}(n=0-2)$, to the reaction system as described in Table 3, has the following effects:

1. Virtually no direct $\mathrm{Cl}$ adduct formation $[\mathrm{M}+\mathrm{Cl}]^{+}$ or $[\mathrm{M}-\mathrm{H}+\mathrm{Cl}]^{+}$is observed, though the addition reactions are calculated to be exergonic in the range of $\Delta \mathrm{G}_{\mathrm{R}}=-0.22 \mathrm{eV}$ up to $-0.96 \mathrm{eV}$. As shown in Figure 3, photolysis of $170 \mathrm{ppm} \mathrm{CCl}_{4}$ results in about $17 \mathrm{ppb} \mathrm{Cl}$ atoms (single laser pulse at $193 \mathrm{~nm}$, $10 \mathrm{~ns}, 1 \mathrm{~mJ}$ ). One reasonable explanation for missing $\mathrm{Cl}$-adducts is the fast competing Reaction no. 10 (Table 1) rapidly trapping initially formed $\mathrm{Cl}$ atoms as $\mathrm{ClOO}$, which at 1 bar rapidly decomposes to recycle $\mathrm{Cl}$ atoms. Thus, the $\mathrm{Cl}$ concentration becomes quasi-stationary and might be too low to react swiftly enough with primary radical cations.

2. A $\mathrm{ClO}$ adduct with the characteristic chlorine isotope pattern at masses $\mathrm{m} / \mathrm{z}=253 / 255$ is observed when $\mathrm{O}_{2}$ and $\mathrm{Cl}$ are present in large quantities. CID of $m / z=253$ leads to mass $m / z=218$, assigned to $[\mathrm{M}+\mathrm{O}]^{+}$. It follows that the chlorine atoms react to form the relatively stable $\mathrm{ClO}$ radical (via Reactions no. 10 and no. 12, Table 1), which then readily adds to the aromatic ring system.

3. The presence of $\mathrm{Cl}$ atoms drastically changes the relative intensity distribution among the oxygenated products, favoring the most stable phenoxy type species $(m / z=217)$ as observed before. Obviously, the H-abstraction reactions (nos. 3/4/5/6, Table $2)$, following the initial oxygen addition step, are strongly supported by the exergonic formation of $\mathrm{HCl}$ (no. 17, Table 2).

The signal intensity of the sum of the oxygenated products relative to the intensity of the pyrene radical cation is also drastically changed, up to the complete loss of $\mathrm{M}^{\bullet+}$. It is unlikely that chlorine atoms or any other of the $\mathrm{Cl}$ containing radical species abstract an 
$\mathrm{H}$-atom from the carbon skeleton of $\mathrm{M}^{\bullet+}$ other than in the $\mathrm{O}$ atom activated positions (cf. Figure 4 and $\Delta \mathrm{G}_{\mathrm{R}}$ Table 2, nos. 17/18/19 compared with no. 7). Thus the previously excluded second reaction pathway via the pyrenyl cation $[\mathrm{M}-\mathrm{H}]^{+}$is also not favored in the presence of chlorine species.

In summary, $\mathrm{Cl}$ atoms do not add directly to $\mathrm{M}^{\bullet+}$ nor do they abstract $\mathrm{H}$-atoms at any appreciable rates. Nevertheless, their presence strongly promotes the oxygenation of $\mathrm{M}^{\bullet+}$ to yield $[\mathrm{M}+\mathrm{O}-\mathrm{H}]^{+}$via $\mathrm{H}-$ abstraction after the primary oxygenation step. Note that the absorption cross sections of chlorinated methanes are generally two orders of magnitude higher than of $\mathrm{H}_{2} \mathrm{O}$ and more than four orders of magnitude higher than of $\mathrm{O}_{2}$.

\section{Summary and Conclusion}

We have demonstrated that neutral radical initiated ion-molecule chemistry is responsible for ion transformation upon direct APPI and we marked its importance when interpreting and mechanistically investigating APPI and APLI $(\lambda<200 \mathrm{~nm})$ mass spectra. Although the presence of oxygenated aromatic hydrocarbons in API is known since 1983, when Mahle et al. observed hydroxylated benzene upon APCI of benzene [49], no evidence for neutral radical chemistry was discussed until 2005, when Frey et al. investigated oxidized proteins observed upon APCI. They tentatively explained their observations in analogy to the atmospheric degradation of organic compounds with $\mathrm{OH}$ radicals [50]. However, the large extent to which neutral radical chemistry is driven in an API source initiated by VUV light absorption or via electrical discharge processes (coronas) has not been recognized yet. Up to now, many reported but unexplained APPI/APCI mass signals are vaguely attributed to impurities or to reactions with closed shell molecules, such as $\mathrm{H}_{2} \mathrm{O}$ and $\mathrm{O}_{2}$. Kauppila et al. [51] and also Robb et al. [52] observed abundant signals of $[\mathrm{M}+15 / 16 / 17]^{+}$upon toluene dopant assisted APPI. Addition of $\mathrm{CHCl}_{3}$ and $\mathrm{H}_{2} \mathrm{O}$ was reported to enhance these signals to become base peaks. We believe that the same mechanisms as discussed in the present paper are responsible for their observations.

Our investigations focused on the fate of gaseous pyrene within an API-source operated with a well defined neutral radical chemistry present. Hence, several neutral radical reaction sequences were deliberately excluded to facilitate a step-by-step investigation of the oxidation processes of the analyte within our experiments. The results of mass spectrometric product analysis, kinetic simulations, and quantum chemical calculations strongly support the oxidation of pyrene radical cations via the $\mathrm{OH}$ radical addition channel with subsequent $\mathrm{H}$ atom abstraction steps finally yielding a phenoxy type structure. The summed peak areas of oxygenated products relative to the primary radical ion as well as the relative peak abundances among the oxygenated products turned out to be highly dependent on the amount of neutral radicals present. The residence time within the API source, i.e., the reaction time provided for the oxidation process, shows a comparable trend for the observed relative signal distribution. Furthermore, kinetic modeling and comparison with experimental data yielded a rate constant estimate of $\mathrm{k}=$ $(1.9 \pm 0.9) \times 10^{-9} \mathrm{~cm}^{3}$ molecule ${ }^{-1} \mathrm{~s}^{-1}$ for the addition reaction of $\mathrm{OH}$ to the pyrene radical cation.

It is stressed that these results cannot be generalized. We provide a summary of the most relevant neutral radical reactions that have to be considered when mechanistic studies are carried out in an API source. However, this chemistry becomes increasingly complex when further compounds, e.g., solvents, are added. Many radical species potentially affect the fate of primarily generated analyte ions and may open new ways of ion transformation processes. These processes become clearly visible at low primary ion concentrations and might be far less observable when charged species are in excess. In this case, the neutral radicals are merely titrated away and the remaining ion population is detected without notable transformation products present. However, APLI is designed as an ultra-trace detection technique and, thus, in most applications rather low ion concentrations prevail in the source region.

Recent experiments, which are still under investigation, confirmed oxidation processes of alkanes upon APPI. When adding heptane or hexane, solvents commonly used in normal phase liquid chromatography, to the standard APPI ion source (Figure 1, top), excitation with $193 \mathrm{~nm}$ radiation results in three signals, $[\mathrm{M}+$ $13]^{+},[\mathrm{M}+15]^{+}$, and $[\mathrm{M}+17]^{+}$. The signal $[\mathrm{M}+13]^{+}$ eventually shows the highest abundance when the neutral radical concentration or the reaction time is increased. First experiments confirmed that these signals are attributable to oxygenated products. Kauppila et al. [51] observed analogous mass spectra with pure hexane added to their APPI MS setup.

We strongly believe that mechanistic investigations of the processes prevailing in APPI or APCI and VUV APLI at the elementary reaction level need to address the impact of neutral radical chemistry. This appears to be of paramount importance when parent radical cation concentrations are low, i.e., in trace and ultra-trace analytical applications. Consideration of this chemistry might give new perspectives of interpreting the generation of quasi-molecular ions via $\mathrm{H}$ atom interaction under certain reaction conditions; it might shed some light on the many unknown mass signals currently attributed to "impurities", and it might be the answer to complete loss of primarily generated $\mathrm{M}^{\bullet+}$ below the MS noise level, particularly in direct APPI, resulting in unfavorable detection limits.

\section{Acknowledgments}

The authors acknowledge financial support for this work by the German Research Foundation (DFG) under contracts BE 2124/6-1 and BE 2124/4-1. Generous support of Bruker Daltonics, Bremen, 
Germany, is gratefully acknowledged. They thank Dr. Daria Kokh, University of Wuppertal, for computational advice.

\section{References}

1. Schrader, W.; Panda, S. K.; Brockmann, K. J.; Benter, T. Characterization of nonpolar aromatic hydrocarbons in crude oil using atmospheric pressure laser ionization and Fourier transform ion cyclotron resonance mass spectrometry (APLI FT-ICR MS). Analyst 2008, 133, 867-869.

2. Schmitt-Kopplin, P.; Englmann, M.; Rossello-Mora, R.; Schiewek, R.; Brockmann, K. J.; Benter, T.; Schmitz, O. J. Combining chip-ESI with APLI (cESILI) as a multimode source for analysis of complex mixtures with ultrahigh-resolution mass spectrometry. Anal. Bioanal. Chem. 2008, 391, 2803-2809.

3. Constapel, M.; Schellenträger, M.; Schmitz, O. J.; Gäb, S.; Brockmann, K. J.; Giese, R.; Benter, T. Atmospheric-pressure laser ionization: A novel ionization method for liquid chromatography/mass spectrometry. Rapid Commun. Mass Spectrom. 2005, 19, 326-336.

4. Schiewek, R.; Schellenträger, M.; Mönnikes, R.; Lorenz, M.; Giese, R.; Brockmann, K. J.; Gäb, S.; Benter, T.; Schmitz, O. J. Ultrasensitive determination of polycyclic aromatic compounds with atmosphericpressure laser ionization as an interface for GC/MS. Anal. Chem. 2007, $79,4135-4140$

5. Schiewek, R.; Mönnikes, R.; Wulf, V.; Gäb, S.; Brockmann, K. J.; Benter, T.; Schmitz, O. J. A universal ionization label for the APLI-(TOF)MS analysis of small molecules and polymers. Angew. Chem. Int. Ed. 2008, 47, 9989-9992.

6. Cheng, B. M.; Bahou, M.; Chen, W. C.; Yui, C. H.; Lee, Y. P.; Lee, L. C. Experimental and theoretical studies on vacuum ultraviolet absorption cross sections and photodissociation of $\mathrm{CH}_{3 \mathrm{OH}}, \mathrm{CH}_{3} \mathrm{OD}, \mathrm{CD}_{3} \mathrm{OH}$, and $\mathrm{CD}_{3} \mathrm{OD}$. J. Chem. Phys. 2002, 117, 1633-1640.

7. Kanda, K.; Nagata, T.; Ibuki, T. Photodissociation of some simple nitriles in the extreme vacuum ultraviolet region. Chem. Phys. 1999, 243 $89-96$

8. Hatano, Y. Interaction of photons with molecules-cross-sections for photoabsorption, photoionization, and photodissociation. Radiat. Environ. Biophys. 1999, 38, 239-247.

9. Gingell, J. M.; Mason, N. J.; Walker, I. C.; Marston, G.; Zhao, H.; Siggel, M. R. F. The electronic states of cyclopropane studied by VUV absorption and electron energy-loss spectroscopies. J. Phys. B At. Mol. Opt. Phys. 1999, 32, 2729-2744.

10. Nee, J. B.; Suto, M.; Lee, L. C. Photoexcitation processes of $\mathrm{CH}_{3} \mathrm{OH}-$ Rydberg states and photofragment fluorescence. Chem. Phys. 1985, 98 , $147-155$

11. Nuth, J. A.; Glicker, S. The vacuum ultraviolet-spectra of $\mathrm{HCN}, \mathrm{C}_{2 \mathrm{~N} 2}$, and $\mathrm{CH}_{3}$ CN. J. Quant. Spectros. Radiat. Transfer. 1982, 28, 223-231.

12. Eden, S.; Limao-Vieira, P.; Kendall, P.; Mason, N. J.; Hoffmann, S. V.; Spyrou, S. M. High resolution photo-absorption studies of acrylonitrile, $\mathrm{C}_{2} \mathrm{H}_{3} \mathrm{CN}$, and acetonitrile, $\mathrm{CH}_{3} \mathrm{CN}$. Eur. Phys. J. D. 2003, 26, 201-210.

13. Russell, B. R.; Edwards, L. O.; Raymonda, J. W. Vacuum ultravioletabsorption spectra of chloromethanes. J. Am. Chem. Soc. 1973, 95, 2129-2133.

14. O'Brien, R.; Furgeson, A.; Arkinstall, D. Role of non-ionizing photon absorption in the observed mass spectra produced by an Atmospheric Pressure Photoionization-LC-MS source. Proceedings of the 55th ASMS Conference on Mass Spectrometry and Allied Topics; Indianapolis, IN, June 2007

15. Le Page, V.; Keheyanb, Y.; Snowa, T.P.; Bierbaum, V. M. Gas phase chemistry of pyrene and related cations with molecules and atoms of interstellar interest. Int. J. Mass Spectrom. 1999, 187, 949-959.

16. Gioumousis, G.; Stevenson, D. P. Reactions of gaseous molecule ions with gaseous molecules. 5. Theory. J. Chem. Phys. 1958, 29, 294-299.

17. Ruzicka, K.; Mokbel, I.; Majer, V.; Ruzicka, V.; Jose, J.; Zabransky, M. Description of vapor-liquid and vapor-solid equilibria for a group of polycondensed compounds of petroleum interest. Fluid Phase Equilib. 1998, 148, 107-137.

18. Jelezniak, M.; Jelezniak, I. CHEMKED: Chemical Kinetics of Gas Phase Reactions, Chemked Version 3.3; Darmstadt, Germany, 2007.

19. Manion, J. A.; Huie, R. E.; Levin, R. D.; Burgess, D. R. Jr.; Orkin, V. L.; Tsang, W.; McGivern, W. S.; Hudgens, J. W.; Knyazev, V. D.; Atkinson, D. B.; Chai, E.; Tereza, A. M.; Lin, C.-Y.; Allison, T. C.; Mallard, W. G.; Westley, F.; Herron, J. T.; Hampson, R. F.; Frizzell, D. H. NIST Chemical Kinetics Database, NIST Standard Reference Database 17, version 7.0 (Web Version), Release 1.4.3, Data version 2008.12, National Institute of Standards and Technology, Gaithersburg, MD. Web address: http://kinetics.nist.gov/.

20. Frisch, M. J.; Trucks, G. W.; Schlegel, H. B.; Scuseria, G. E.; Robb, M. A.; Cheeseman, J. R.; Montgomery, J. A. Jr.; Vreven, T.; Kudin, K. N.; Burant, J. C.; Millam, J. M.; Iyengar, S. S.; Tomasi, J.; Barone, V.; Mennucci, B.; Cossi, M.; Scalmani, G.; Rega, N.; Petersson, G. A.; Nakatsuji, H.; Hada, M.; Ehara, M.; Toyota, K.; Fukuda, R.; Hasegawa, I.: Ishida, M.; Nakajima, T.; Honda, Y.; Kitao, O.; Nakai, H.; Klene, M.; Li, X.; Knox, J. E.; Hratchian, H. P.; Cross, J. B.; Bakken, V.; Adamo, C.; Jaramillo, J.; Gomperts, R.; Stratmann, R. E.; Yazyev, O.; Austin, A. J.; Cammi, R.; Pomelli, C.; Ochterski, J. W.; Ayala, P. Y.; Morokuma, K.; Voth, G. A.; Salvador, P.; Dannenberg, J. J.; Zakrzewski, V. G.; Dapprich, S.; Daniels, A. D.; Strain, M. C.; Farkas, O.;
Malick, D. K.; Rabuck, A. D.; Raghavachari, K.; Foresman, J. B.; Ortiz, J. V.; Cui, Q.; Baboul, A. G.; Clifford, S.; Cioslowski, J.; Stefanov, B. B.; Liu, G.; Liashenko, A.; Piskorz, P.; Komaromi, I.; Martin, R. L. Fox, D. J.; Keith, T.; Al-Laham, M. A.; Peng, C. Y.; Nanayakkara, A.; Challacombe, M.; Gill, P. M. W.; Johnson, B.; Chen, W.; Wong, M. W.; Gonzalez, C.; Pople, J. A. Gaussian 03, Revision C. 02; Gaussian, Inc.:, Wallingford CT, 2004

21. Dennington, R. II; Keith, T.; Millam, J. GaussView, Version 4.1; Semichem, Inc., Shawnee Mission, KS, 2007.

22. Stephens, P. J.; Devlin, F. J.; Chabalowski, C. F.; Frisch, M. J. Ab-initio calculation of vibrational absorption and circular-dichroism spectra using density-functional force-fields. J. Phys. Chem. 1994, 98, 1162311627.

23. Garifzianova, G. G.; Tsyshevskii, R. V.; Shamov, A. G.; Khrapkovskii, G. M. A. quantum-chemical study of n-butane and of butane cation radical. Int. J. Ouantum. Chem. 2007, 107, 2489-2493.

24. Laali, K. K.; Okazaki, T.; Galembeck, S. E. Stable ion and electrophilic chemistry of fluoranthene-PAHs. J. Chem. Soc. Perkin. Trans. 2 2002, 3, 621-629.

25. Langhoff, S. R. Theoretical infrared spectra for polycyclic aromatic hydrocarbon neutrals, cations, and anions. J. Phys. Chem. 1996, 100, 2819-2841.

26. Rodriquez, C. F.; Shoeib, T.; Chu, I. K.; Siu, K. W. M.; Hopkinson, A. C. Comparison between protonation, lithiation, and argentination of 5-oxazolones: A study of a key intermediate in gas-phase peptide sequencing. J. Phys. Chem. A 2000, 104, 5335-5342.

27. Wood, J. M.; Kahr, B.; Hoke, S. H.; Dejarme, L.; Cooks, R. G.; Benamotz, D. Oxygen and Methylene Adducts of C-60 and C-70. J. Am. Chem. Soc. 1991, 113, 5907-5908.

28. Ling, Y.; Gotkis, Y.; Lifshitz, C. Time-dependent mass-spectra and breakdown graphs. 18. Pyrene. Eur. Mass Spectrom. 1995, 1, 41-49.

29. Lifshitz, C. Energetics and dynamics through time-resolved measurements in mass spectrometry: Aromatic hydrocarbons, polycyclic aromatic hydrocarbons and fullerenes. Int. Rev. Phys. Chem. 1997, 16 113-139.

30. Lias, S. G.; Bartmess, J. E.; Liebman, J. F.; Holmes, J. L.; Levin, R. D. Mallard, W. G. Gas phase ion and neutral thermochemistry. J. Phys. Chem. Ref. Data. 1988, 17 (Suppl. 1).

31. Herzberg, G. Molecular spectra and molecular structure; Van Nostrand Reinhold Company: New York, NY, 1966.

32. Nourse, B. D.; Cox, K. A.; Cooks, R. G. Ion-molecule chemistry of pyrene in an ion-trap mass-spectrometer. Org. Mass Spectrom. 1992, 27, $453-462$.

33. Seinfeld, J. H.; Pandis, S. N. Atmospheric Chemistry and Physics_From Air Pollution to Climate Change; John Wiley and Sons, Inc.: New York, NY, 1998.

34. Wutz, M.; Adam, H.; Walcher, W. Theorie und Praxis der Vakuumtechnik, 4th ed.; Friedr. Vieweg und Sohn: Braunschweig/Wiesbaden, Germany, 1988.

35. Michalke, A. A note on the viscous pipe-flow of a compressible fluid with heat-transfer. Ing. Arch. 1987, 57, 377-392.

36. Kersten, H; Lorenz, M; Wissdorf, W; Funcke, V; Brockmann, K.-J. Benter, T., unpublished. (In preparation for publication in JASMS 2009.)

37. Imasaka, T.; Moore, D. S.; Vo-Dinh, T. Critical assessment: Use of supersonic jet spectrometry for complex mixture analysis (IUPAC Technical Report). Pure Appl. Chem. 2003, 75, 975-998.

38. Jones, C. M.; Asher, S. A. Ultraviolet resonance Raman-study of the pyrene S4, S3, and S2 excited electronic states. J. Chem. Phys. 1988, 89, 2649-2661.

39. Chihara, K.; Baba, H. Quenching of dual fluorescences of pyrene vapor by high-pressure oxygen or nitric oxide. Chem. Phys. 1977, 25, 299-306.

40. Baba, H.; Aoi, M. Vapor-phase fluorescence-spectra from second excited singlet-state of pyrene and its derivatives. J. Mol. Spectrosc. 1973, 46, 214-222.

41. Baba, H.; Nakajima, A.; Aoi, M.; Chihara, K. Fluorescence from second excited singlet state and radiationless processes in pyrene vapor. J. Chem. Phys. 1971, 55, 2433-2438.

42. Chihara, K.; Baba, H. Effects of foreign gases on dual fluorescences of pyrene vapor. Bull. Chem. Soc. Jpn. 1975, 48, 3093-3100.

43. Borisevich, N. A.; Vodovatov, L. B.; Dyachenko, G. G.; Petukhov, V. A.; Semenov, M. A. Spectroscopy of pyrene clusters formed in a supersonic jet. Laser Phys. 1997, 7, 400-402.

44. Malloci, G.; Mulas, G.; Joblin, C. Electronic absorption spectra of PAHs up to vacuum UV-towards a detailed model of interstellar PAH photophysics. Astron. Astrophys. 2004, 426, 105-117.

45. Mendes, M. A.; Moraes, L. A. B.; Sparrapan, R.; Eberlin, M. N.; Kostiainen, R.; Kotiaho, T. Oxygen atom transfer to positive ions: A novel reaction of ozone in the gas phase. J. Am. Chem. Soc. 1998, 120, 7869-7874.

46. Atkinson, R.; Arey, J.; Zielinska, B.; Aschmann, S. M. Kinetics and nitro-products of the gas-phase $\mathrm{OH}$ and $\mathrm{NO}_{3}$ radical-initiated reactions of naphthalene-D8, fluoranthene-D10, and pyrene. Int. J. Chem. Kinet. 1990, 22, 999-1014.

47. Page, V. L. Chemical constraints on organic cations in the interstellar medium. J. Am. Chem. Soc. 1997, 119, 8373-8374.

48. Frerichs, H.; Tappe, M.; Wagner, H. G. Comparison of the reactions of monocyclic and polycyclic aromatic-hydrocarbons with oxygen-atoms. Ber. Bunsen. Ges. Phys. Chem. 1990, 94, 1404-1407. 
49. Mahle, N. H.; Cooks, R. G.; Korzeniowski, R. W. Hydroxylation of aromatic-hydrocarbons in mass-spectrometer ion sources under atmospheric-pressure ionization and chemical ionization conditions. Anal. Chem. 1983, 55, 2272-2275.

50. Frey, B. L.; Lin, Y.; Westphall, M. S.; Smith, L. M. Controlling gas-phase reactions for efficient charge reduction electrospray mass spectrometry of intact proteins. J. Am. Soc. Mass Spectrom. 2005, 16, 1876-1887.
51. Kauppila, T. J.; Kuuranne, T.; Meurer, E. C.; Eberlin, M. N.; Kotiaho, T.; Kostiainen, R. Atmospheric pressure photoionization mass spectrometry. Ionization mechanism and the effect of solvent on the ionization of naphthalenes. Anal. Chem. 2002, 74, 5470-5479.

52. Robb, D. B.; Blades, M. W. Effects of solvent flow, dopant flow, and lamp current on dopant-assisted atmospheric pressure photoionization (DA-APPI) for LC-MS. Ionization via proton transfer. J. Am. Soc. Mass Spectrom. 2005, 16, 1275-1290. 